\title{
Comparing the self-perceptions and efficacy of Spanish heritage language learners as authors: In search of an effective writing process
}

Una comparación entre la autopercepción y la eficiencia de los aprendices de español de herencia como autores: en búsqueda de un proceso de escritura efectiva

Laura Elena Valentín Rivera Kansas State University, Department of Modern Languages

\begin{abstract}
Within the context of the United States of America, heritage language learners (HLLS) are defined as individuals that develop a minority language at home, in this case Spanish, before English, through early exposure (Valdes, 2001). Their academic instruction, however, takes place mainly, if not exclusively, in the mainstream language: English. The present study surveys the self-perception of twelve Spanish HLLS in regard to performance (i.e., strategies) and attributes (i.e., efficacy) as writers, aiming to determine whether these views match their realities. To this end, subjects engaged in a three-stage process, namely completing a question-

and writing strategies, composing an argumentative essay, and engaging in a posthoc interview. Results suggest that the self-perceptions of participants commonly mismatched their realities; subjects often approached the writing process in a way differing from the one originally stated. Additionally, some strategies within specific writing stages - for example, focusing on content while revising vs. outlining while planning — seemingly contribute to the crafting of more effective texts. Findings contribute knowledge and practical advice to facilitate the development of efficient writing strategies, ultimately empowering HLLS as authors.
\end{abstract} naire pertaining to linguistic background

* K-State made this study and contributions possible.

Thank you MSJ for being you — and for your help. 
Keywords: Spanish as a heritage language; essay writing process; text revision strategies; text structure planning; writing proficiency

\section{Resumen}

En el contexto de los Estados Unidos, el término aprendices de herencia se refiere a aquellos individuos que adquieren una lengua minoritaria en casa, en este caso el español, debido a una exposición temprana (Valdés, 2001). Sin embargo, la preparación académica que reciben es principalmente en inglés. Este estudio analiza la autopercepción de doce aprendices de herencia del español en referencia a su desempeño (estrategias de escritura) y sus atributos (efectividad al redactar) como autores, con la intención de establecer si sus percepciones concuerdan con sus realidades. Para este fin, los participantes completaron una batería tripartita consistente en un cuestionario sobre sus antecedentes lingüísticos y estrategias de escritura, un ensayo persuasivo y una entrevista. Los resultados sugieren que las autopercepciones de los participantes difirieron de sus realidades; los aprendices frecuentemente abordaron el proceso de escritura de una manera diferente a la que inicialmente declararon. También, algunas estrategias - por ejemplo, enfocarse en cuestiones de contenido al hacer revisiones en lugar de crear un esquema- fueron más eficientes que otras para construir textos más efectivos. Este conocimiento y los consejos prácticos aquí ofrecidos pretenden facilitar la formación de escritores eficaces a través del desarrollo de estrategias puntuales, para así empoderar a los aprendices de herencia del español como autores.

Palabras clave: español como lengua de herencia; proceso de escritura ensayística; estrategias de revisión de textos; planeación de la estructura de textos; dominio de la escritura 


\section{Introduction}

Spanish heritage language learners (hereafter referred to as HLLS), i.e., individuals that are exposed to a minority language at home from an early age (Valdés, 2001), in this case Spanish, often show a fluctuating command of oral proficiency of the heritage language (Blake \& Zyzik, 2003). Additionally, this population displays a linguistic variety that differs from that of native speakers in syntactic, morphological, and lexical terms (Pascual y Cabo \& Rothman, 2012). In particular, the morphology of Spanish as a heritage language (HL) may encompass matters of gender, such as the use of the masculine by default (Montrul \& Bowles, 2009; Venezuela, Faure, Ramírez-Trujillo, Barski, Pangtay \& Díez, 2012). Some syntactic features, on the other hand, reflect linguistic transfers from English (e.g., mofle, billes, troca) (Valdés, 1997), and document the continued use of the syntactic construction patrás to express a returning state (Lipski, 2008), as in llamar patrás (i.e., to call back), dar patrás (i.e., to give back) and pagar patrás (i.e., to pay back).

Despite the competence of Spanish HLLs to produce language orally, this linguistic population struggles when it comes to engaging in written communications (García, 2002; Chevalier, 2004; Valdés, 2005; Callahan, 2010; Mikulski \& Elola, 2011; Colombi \& Harrington, 2012; Elola \& Mikulski, 2013). This issue has driven research on the writing performances of HLLs with a dual focus: the text and the process (Norris \& Manchón, 2012; Williams, 2012). Investigations addressing the text, i.e., the final version of manuscripts produced by HLLs, have focused mainly on the identification of discursive features commonly used by these authors, mainly rhetorical trends (García, 2002; Spicer-Escalante, 2005). On the other hand, research addressing the process has surveyed primarily the strategies used by HLLs to construct a written assignment, in addition to the way that these learners apply them (Schwartz, 2003; Mikulski \& Elola, 2011; Elola \& Mikulski, 2013). However, the research following a process approach has not explored the perception of HLLs on their own efficacy when writing. This type of research has not focused on whether HLLs are aware of the techniques they use, or whether they just happen to be fluid writers either. Exploring these matters would reveal whether HLLs, as authors, have specific goals in mind that influence how they approach the writing process (i.e., planning, craf- 
ting, revising strategies), as well as briefing us on how effective these actions are. This knowledge would subsequently guide Spanish instructors to effectively facilitate the development of literacy skills, especially among HLLs. Therefore, the present study surveys the writing strategies employed by HLLs to complete an argumentative text. More specifically, this work explores the following:

a) the perceptions of HLLs on their own effectiveness as writers and on the difficulties they face as authors (i.e., coping with grammar-related issues),

b) whether HLLs usually carry out any sort of planning and revisions on their own,

c) the effectiveness resulting from these crafting and editing procedures.

Additionally, some pedagogical suggestions concerning the facilitation of the development of literacy in the heritage classroom are provided to ultimately empower Spanish HLLs as writers.

\section{Literature review}

The following section describes the findings about the construction of texts by Spanish HLLs at the individual level, especially when using rhetorical elements and strategies regarding time allocation.

\subsection{Texts written by heritage language learners: Rhetoric on individual work}

Research on the writing abilities of HLLs from the text perspective, seen as the ultimate printed proof of discursive and linguistic written performance, has explored primarily the rhetoric maneuvers employed by this population (García, 2002; Spicer-Escalante, 2005). More specifically, the study by García (2002) explored the written work of 12 English/Spanish bilinguals unable to become certified Spanish instructors due to their limited literacy skills. To this end, participants were asked to complete an essay in Spanish. According to García, participants seemingly wrote "backwards across languages" (2002: 246), as their texts reflected the typical "English essayist rhetorical tradition that [the] remedial writing courses focus on" (2002: 248). Four of these features are worth 
mentioning. First, an overwhelming use of the passive voice was observed. Second, the organization and structure of paragraphs reflected an introduction that conveyed a thesis statement, three paragraphs outlining the assertions of the participant were established and supported, followed by a conclusion restating the primary premise of the text. Third, metaphors and poetic language were not used. Fourth, a very few adjectives were employed. According to the researcher, all of these characteristics are very uncommon in Spanish essay writing.

On the other hand, Spicer-Escalante (2005) worked with 23 participants: 10 second-generation HLLs exposed to Spanish academic learning since college, eight foreign language learners (FLLs with English as their L1), and five Mexican Spanish native speakers. All subjects were required to write two essays. The first task consisted of an English argumentative essay about college education - analyzed through the Toulmin informal reasoning model. The second assignment encompassed crafting a Spanish persuasive text about drug usage, examined through the Persuasive appeals model. ${ }^{1}$ Based on Toulmin's scheme, Spicer-Escalante concluded that when writing in either language (but mainly in Spanish), HLLs tend to support their thesis statement with over-generalized knowledge embedded within "everybody-knows" statements. Thus, Spanish HLLs' texts lacked statistical facts or expert opinions, while FLLS employed both objective resources to support their statements. The persuasive model, on the other hand, suggested that HLLs construct their arguments through analogies, testimonies and examples related to their personal life. Thus, HLLs addressed the audience directly, and attempted to set emotional connections by sharing meticulous descriptions of their everyday experiences. In contrast, FLLs used similar resources sparingly in the introduction only, through direct quotes. It is worth mentioning that the most recent work by Spicer-Escalante (2015) has also suggested that a writing task (when composing narratives) is approached differently by bilingual writers, according to the language of choice (i.e., English or Spanish).

1 The Persuasive Appeals Analysis model also includes three parts: the rational, credibility, and affective appeals, just like the Toulmin Analysis (Connor \& Lauer, 1985). 


\subsection{Processes of heritage language learners when writing: Text construction strategies}

Investigating on the writing process, Schwartz (2003) worked with three second-generation female HLLs whose academic education was exclusively in English. The objective of this study was to gain a deeper insight into a) how HLLs approach writing in Spanish, and b) the composing strategies most frequently used by them. To this end, participants were required to engage in three stages to complete a composition: 1) planning, 2) composing, and 3) revising. Additional information regarding the proficiency level in Spanish of each subject and his/her common writing habits was gathered through two questionnaires. Furthermore, subjects participated in a post-hoc interview and a think-aloud protocol to share the rationale for their preferred writing techniques. The completion of both of these procedures showed a persistent oral interference that ultimately displayed constant transfers from English. Also, the results regarding the three writing processes (i.e., planning, composing, and revising) suggested that the stage that participants were most invested in was composing, where three main strategies were employed: rehearsing, repeating, and re-scanning. It is worth mentioning that all of these were carried out vocally/out loud. As such, when "rehearsing", HLLs tended to test their ideas out loud before including them in the text. "Repeating", the most popular technique, consisted of reading aloud specific words or phrases after having written them down. Meanwhile, "re-scanning" included aloud re-reading of extended text extracts to confirm their relevance regarding the aim of the assignment. To note, however, despite the right verbalization of most forms, the participants frequently wrote them down incorrectly. Based on these observations, Schwartz (2003) proposed that although the oral initiatives of HLLs seeked linguistic correctness, they ended up being counterproductive. Vocalization when writing also trespassed the boundaries of oral communication, given the resemblance of some written forms with informal everyday oral discourse, perhaps due to the lack of academic preparation in the heritage language by the writer.

Following a cognitive-oriented approach, Mikulski and Elola (2011) explored the writing performance of 12 HLLs in a third-year Spanish language class. Their study focused primarily on the distribution of time when plan- 
ning, writing and revising a text similar to Schwartz (2003). A secondary goal was to assess linguistic accuracy and fluency of the final version of the text. To this end, subjects engaged in a two-stage process. First, they completed a background questionnaire regarding their previous experience with Spanish (both at home and at school). Afterwards, based on two excerpts of a movie about a Hispanic family in the us, participants were asked to complete two comparison-and-contrast essay questions: one in Spanish and one in English. In order to better keep a record of the time allocation, the entire writing process was recorded by Camtasia, "a software program that records all activities on the computer screen in real time" (Mikulski \& Elola, 2011: 721). Unlike Schwartz (2003), whose participants were mainly engaged in the composing stage, subjects in the study by Mikulski and Elola (2011) invested a substantial time on planning, especially in Spanish. However, the texts written in English ultimately displayed higher fluidity and linguistic accuracy. According to the researchers, HLLs undertook more (meaningful) revisions when writing in the socially and academic dominant language (i.e., English).

\section{Present study}

Because of its limited dual focus regarding the exploration of rhetorical features (García, 2002; Spicer-Escalante, 2005) and composing strategies (Schwartz, 2003; Mikulski and Elola, 2011), the current research on the Spanish literacy performance of HLLs offers only an approximation into the writing skills spectrum. An aspect that has been overlooked is whether HLLs construct their written assignments based on strategic approaches, and whether these are effective. Additionally, little attention has been paid to the self-perception HLLs as writers. This particular type of knowledge is essential to better understand HLLs as authors, given that 'the relationship between learners' beliefs, attitudes and actions is complex and unpredictable" (Storch, 2013: 98) commonly describing distorted realities. For the above, the present study aims to shed some light on these overseen issues by addressing the following research questions:

1) What are the self-perceptions of HLLs about their efficacy as writers and the challenges they face throughout the writing process? 
2) What are the self-perceptions of HLLs regarding the planning strategies used by them before engaging in the writing process, if any? Do their ways to approach the planning of the text match the descriptions they offered when being interviewed?

3) What are the self-perceptions of HLLs regarding the revising strategies used by them during text elaboration and after completing a text, if any? Do their ways to carry out revisions of the text match the descriptions they offered when being interviewed?

4) Did specific writing strategies (i.e., planning vs. revising) resulted in more efficient argumentative texts?

\section{Methods}

This section provides a detailed description of the settings where this study took place, the background of the participants, the materials used to gather the data that supported our results, and the processes that led to the conclusions.

\subsection{Settings and participants}

This study was conducted in a large public university in the American Midwest that offers a Spanish course for HLLs. The objectives of this course focus around improving the reading and writing skills, particularly addressing formal and academic Spanish, as well as oral communication skills (in the classroom itself), using a formal register. Twelve students (9 females, 3 males; 19-23 years old) that enrolled in this course during the spring of 2016 agreed to participate in this research project. All HLLs declared to have been born in the United States of America — thus belonging to a second generation of immigrants onward — and considered Spanish to be their first language, as they were exposed to it from birth. Additionally, these HLLs declared to speak Spanish regularly to communicate with at least one of their relatives. Participants' mothers and grandmothers $(91.6 \%)$ were reportedly the people they more often talk to in Spanish, either because the relatives in question had a low proficiency of English $(58.3 \%)$, or simply because Spanish is, by choice, the predominant language at home (41.6\%). 


\subsection{Materials and methods}

Participants completed the following three data collection activities, in order of appearance: 1) an online survey, 2) a short writing assignment, and 3) a face-toface interview. The survey included items aiming to obtain information about the linguistic background of the subjects, as well as their previous experience with drafting (academic) texts in Spanish. The short writing assignment consisted of composing a persuasive text, where participants were asked to convince a hypothetical international student to enroll in one of two higher education institutions: a public or a private university. For consistency, participants were told to build a case in favor of the public institution, but they were still required to develop their own arguments in support of their choice. Argumentation was selected as the writing approach of this study for two reasons. First, it was one of the genres that participants were reportedly more familiar with (Table 1). Second, although learners also claimed to be highly experienced with summarizing in Spanish, argumentation tasks have been suggested to require and promote a higher cognitive effort from the authors (Strobl, 2014) since, ideally, writers must reflect on their remarks and support them with facts. Thus, the selection of the argumentative genre was meant to provide participants with a writing comfort zone, given their level of expertise with this genre, which still was a complex task potentially demanding broader planning and revision.

Participants were given 40 minutes to complete the argumentative assignment. Although HLLs were not required to plan their texts, as the study intended to encourage participants to engage in the composing process as they normally would in any other setting, they were provided with some white sheets and a pen, in case they were keen to draft ideas before/during/after composing. All HLLs were also allowed to browse the Internet as needed, but the use of online translators was not allowed. To be able to observe the way in which the entire writing processes proceeded, the Camtasia software was employed. Once subjects completed their texts, they participated in a face-to-face interview, whereby the main researcher inquired on the rationale behind their decisions when dealing with the writing assignment (e.g., skipping the planning process, spending too much time composing but not revising, etc.). Altogether, the three instruments allowed the triangulation of the data, particularly con- 
trasting the actions HLLs reported or believed to have executed with those actually performed.

\section{Analysis}

As mentioned above, the results of this study reflect a triangulation of the data. This information was subsequently analyzed using qualitative, research questions (RQ) 1-3, and quantitative methods, research question 4.

\subsection{Research question 1: Self-perceptions of the participants on their efficacy as authors and issues frequently faced}

The question on the self-perceptions of the participants on their efficacy as authors and the type of issues faced when writing (RQ1) was addressed simply by establishing the percentages of responses provided in the online survey. For instance, in the case of whether participants consider themselves to be proficient authors, the potential answers were either yes or no. Both alternatives were reported as percentages. To strengthen the understanding of the views from the learners, they were required to explain the reasoning behind their answers. At the same time, these responses were sorted into categories that were subsequently used to create a taxonomy to account for each insight, reflection and belief from the participants (see Table 2). To note, a secondary topic explored through RQ1(b) was the common complications that, from their perspective, HLLs face while writing (RQ1). The answers to this topic were also reported based on the percentages of the most common replies.

\subsection{Research questions 2 and 3: Planning and revision strategies before, during, and after writing}

The questions concerning the planning strategies employed by participants before writing (RQ2), as well as the revision approaches applied during and after crafting their texts (RQ3), were also answered based on the categorization of the responses of subjects in the initial online survey and their respective percentages. This information not only revealed which planning and revision strategies 
were claimed to have been commonly used by participants when required to write in Spanish, but also displayed those most frequently used. Subsequently, in order to make a comparison between HLL claims and their actual writing approach, an in-depth analysis of the entire writing process of each participant was performed with Camtasia. The close observation of the visual files allowed the researcher to establish: 1) whether participants actually used the planning and revision strategies reported in their answers, and 2) which techniques were actually employed to prepare and/or review their written work.

\subsection{Research question 4: On the efficacy of the planning and revising strategies}

To assess the degree of efficiency of argumentative texts produced by HLLS (RQ4), two one-way ANOVAs were carried out to establish the correlation of the planning and revision techniques of the participants with essay quality. To this end, all texts crafted by the 12 HLLs were submitted to a grading committee including two Spanish instructors and the researcher herself. A score was assigned using a 100 point grading scale based on an adaptation of a rubric authored by Williams (2005). This grading scale included five core elements: 1) content efficacy (topic-wise, that is: strength of arguments), 2) content efficacy (cohesionand coherence-wise), 3) linguistic precision, 4) lexical precision, and, to a lesser extent, 5) mechanics (i.e., spelling, accent placement and punctuation). To note, the grading committee reached a $93 \%$ consensus on their scores.

\section{Results}

\subsection{Research question 1: Self-perceptions of heritage language learners regarding their own efficacy as writers and issues faced}

Before surveying the self-perceptions of subjects concerning effectiveness, a baseline should be set to facilitate a better understanding of the standpoints of HLLs. In this regard, this section offers an overview of the degree of written fluency in Spanish of participants. Reportedly, before enrolling in this study, most participants $(11 / 12=91.6 \%)$ had some previous experience in writing texts in Spanish, mainly while taking Spanish courses. Participants claimed to 
be acquainted with the following genres: argumentative essays and summaries $(72.7 \%=8$ mentions $)$, letters /e-mails $(54.54 \%=6$ mentions $)$, to-do lists and comparative texts $(27.27 \%=3$ mentions $)$; and expository, narrative, and descriptive compositions $(18.18 \%=2$ mentions $)$; refer to Table 1 .

\begin{tabular}{lcc}
\multicolumn{3}{l}{ TABLE 1. Degree of experience with different writing genres } \\
\hline GENRE & TotAL MENTIONS & PERCENTAGE \\
\hline Argumentative & $8 / 11$ & 72.70 \\
Summary & $8 / 11$ & 72.70 \\
Letters/emails & $6 / 11$ & 54.54 \\
Comparison & $3 / 11$ & 27.27 \\
To-do list & $3 / 11$ & 27.27 \\
Descriptive & $2 / 11$ & 18.18 \\
Expository & $2 / 11$ & 18.18 \\
Narrative & $2 / 11$ & 18.18 \\
\hline
\end{tabular}

It is worth stressing that $50 \%(6 / 12)$ of the HLL participants in this study did not consider themselves to be effective writers, including the only HLL that reported to completely lack any experience regarding writing in Spanish. The reasons that explain their claimed inefficacy include the following: 1) need to develop further linguistic knowledge, 2) composing issues due to reading comprehension limitations, 3) limited lexicon/awareness of grammatical rules, and 4) limited opportunities to practice their writing skills. The remaining $50 \%$ of the HLLS believed their efficiency as authors was related to at least one of five reasons: first, being exposed to bilingual academic preparation; second, having the capacity to elaborate a strong writing structure (cohesion); third, being able to effectively develop and support an argument; fourth, engaging in constant written communications with relatives, and; fifth, being capable of making an efficient transfer of their writing abilities from English to Spanish (refer to Table 2). 
TABLE 2. Efficacy as writers, according to the self-perception of participants

\begin{tabular}{|c|c|c|}
\hline $\begin{array}{c}\text { EFFICACY IN } \\
\text { WRITING }\end{array}$ & REASONING/CODING* & DIRECT COMMENTS FROM HLLS \\
\hline \multirow[t]{5}{*}{ No } & $\begin{array}{l}\text { (1) Need to develop further linguistic } \\
\text { knowledge }\end{array}$ & $\begin{array}{l}\text { "Not very much, I have much to learn before I become an effective } \\
\text { writer in Spanish." [Participant 002] }\end{array}$ \\
\hline & & "Hell no. Because I lack the knowledge in Spanish." [Participant 018] \\
\hline & $\begin{array}{l}\text { (2) Composing issues due to reading } \\
\text { comprehension limitations }\end{array}$ & $\begin{array}{l}\text { "No, I misspell a lot of words and have trouble reading it at times and } \\
\text { comprehending material." [Participant 028] }\end{array}$ \\
\hline & $\begin{array}{l}\text { (3) Limited lexicon/proficiency of } \\
\text { grammatical rules }\end{array}$ & $\begin{array}{l}\text { "No, I do not always use the correct form of the words or use tildes* } \\
\text { the correct way to be considered and effective Spanish writer." [Par- } \\
\text { ticipant 033] }\end{array}$ \\
\hline & (4) Few opportunities to practice & "No, I never have to write anything in Spanish." [Participant 036] \\
\hline \multirow[t]{6}{*}{ Yes } & (a) Solid bilingual academic preparation & $\begin{array}{l}\text { "Yes, because I studied in a bilingual school where Spanish was en- } \\
\text { forced and I was taught by my mother, as I was learning to write." } \\
\text { [Participant 005] }\end{array}$ \\
\hline & $\begin{array}{l}\text { (b) Capacity to —-develop a sound } \\
\text { writing structure (cohesion) }\end{array}$ & $\begin{array}{l}\text { "Yes I do consider myself an effective writer in Spanish, I may have } \\
\text { some grammatical errors but I know how to structure and make it } \\
\text { sound cohesive, I would say." [Participant 012] }\end{array}$ \\
\hline & $\begin{array}{l}\text { (c) Capable to effectively develop and } \\
\text { support an argument }\end{array}$ & $\begin{array}{l}\text { "Yes with some errors. I still have some minor mistakes when writing } \\
\text { in Spanish but I can get my point across for the most part." [Partic- } \\
\text { ipant 023] }\end{array}$ \\
\hline & $\begin{array}{l}\text { (d) Frequent written communications } \\
\text { with relatives }\end{array}$ & $\begin{array}{l}\text { "Yes, because I write in Spanish to my family back in Mexico." [Par- } \\
\text { ticipant 035] }\end{array}$ \\
\hline & $\begin{array}{l}\text { (e) Capable of efficient transfer of wri- } \\
\text { ting skills from English to Spanish }\end{array}$ & $\begin{array}{l}\text { "Yes, I have excellent English writing skills that have largely translat- } \\
\text { ed into Spanish." [Participant 043] }\end{array}$ \\
\hline & & $\begin{array}{l}\text { "Yes, I [consider] myself to be an effective writer in Spanish be- } \\
\text { cause in my mind, I form my argument in English and then, I think } \\
\text { about how I would phrase it correctly in Spanish. I think my ideas } \\
\text { are clear most of the time, but expanding my Spanish vocabulary } \\
\text { could make my writing more effective." [Participant 047] }\end{array}$ \\
\hline
\end{tabular}

* This column reflects the taxonomy that was created based on the general comments that the participants provided regarding to explain their efficacy, or lack of, as writers.

${ }^{\star \star}$ tildes is the word in Spanish to refer to written accent marks.

Regardless of the self-perceptions concerning their abilities as writers, all HLLs reported to be aware of the complexity of crafting Spanish texts. More specifically, half of the participants $(6 / 12=50 \%)$ referred to the challenges of mastering 
mechanics issues (i.e., spelling, accent placement and punctuation). Other challenges mentioned included selecting ideas $(3 / 12=25 \%)$, dealing with grammar-related issues $(2 / 12=16 \%)$, summarizing information - when needed presenting information clearly, and using a formal register $(1 / 12=8.3 \%)$.

\subsection{Research question 2: Self-perceptions of heritage language learners and realities regarding the strategies used before engaging in the writing process}

In addition to surveying the overall self-rating of HLLs as authors, this study also explored the consistency between the strategies claimed as used by these writers before, during, and after composing in Spanish, and their actions when crafting the argumentative text in this study. As to the writing strategies used before engaging in the actual composing process, only $33.33 \%$ of subjects (4/12) - participants 005, 018, 033 and $043^{2}$ — claimed to usually undertake some sort of preparation. Particularly, the four participants that claimed to usually undertake some sort of planning, confirmed to draft an outline (mainly) in Spanish. Two of these subjects (50\%) also claimed to either write down or mentally gather additional ideas in English. Other strategies also reported as used, although to a lesser extent, were asking for help from others (i.e., friends, relatives, or a tutor), and looking up information to take notes $(1 / 4=25 \%)$. Additionally, only one participant $(25 \%)$ reported considering the target audience, in this case the hypothetical international student interested in enrolling in an American university, before developing his/her assignment (refer to Figure 1).

As mentioned above, the entire writing process, which took about 40 minutes, was recorded through Camtasia. The collection of the 12 videos allowed the close observation of the writing behaviors and performances of all HLLs. When contrasting their claims about writing habits in text planification versus their actions, some discrepancies emerged. First, none of the four HLLs that claimed to usually plan their written assignments (participants 005, 018, 033, and 043) actually did so. In the follow-up interview, participant 033 claimed to have carried out a mental outline, which is virtually impossible to prove. Also, when participants 005,018 , and 043 were asked about the reason for not having planned their

2 The presentation of the participants follows a progressive numeric order. 


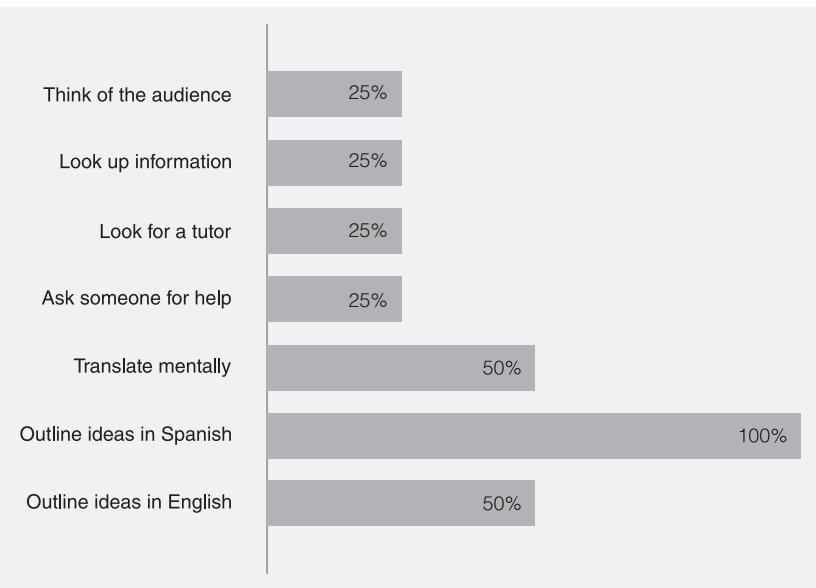

FIGURE 1. Strategies reportedly employed by the participants when planning any text in Spanish

texts, the unanimous reason was that the easiness of the task did not seem to require it. Based on these observations, it is reasonable to state that none of these HLLs carried out the claimed planning strategy: outlining. Instead, three of the eight HLLs that claimed not to plan their written assignments (participants 002, 012, and 037) actually did so. Two other HLLs (participants 023 and 047) claimed to have mentally prepared some ideas. Again, the researcher could not confirm such affirmation.

As regards the verifiable planning strategies used by participants 002, 012, and 037, two techniques stood out: outlining, either on paper or on the computer (participants 002 and 012, respectively), and looking up information through Google (participant 037). To note, when participant 002 outlined on paper, she did so using both languages: English and Spanish. On the other hand, participant 037 gathered academic information on American public and private universities for comparison purposes, as specified in the question. Despite not taking notes about the information searched on Google, participant 037 did includ in his text some of the facts found (e.g., student population size). The post-hoc interview revealed that HLLs that actually carried out some planning did so in or- 
der to support information with facts, avoid time constrictions, and take advantage of their level of familiarity with the topic (to build an effective text).

\subsection{Research question 3: Self-perceptions of heritage language learners and realities regarding the strategies used while crafting and revising texts and their efficacy}

Regarding the writing performance as reported by participants when actually crafting texts in Spanish, all subjects (12/12) claimed to carry out revisions while constructing the text. To this end, two revision strategies were equally popular among participants $(7 / 12=58.3 \%)$ : going over each paragraph during the writing process, and reading the work out loud (to themselves) to identify shortcomings. Additionally, $16.66 \%$ of the HLLs (2/12) claimed to revise each sentence immediately after crafting it, as well as asking others (friends, relatives) to read aloud the texts to them - so that the authors themselves could assess the flow and accuracy of their own ideas (see Figure 2). The latter implies that written assignments were completed outside the Spanish classroom, allowing HLLs to look for assistance from others.

All HLLs also claimed that they usually carry out revisions after composing any assigned writing task in Spanish. More specifically, 66\% (8/12) of HLLs claimed to look for linguistic errors to be addressed (grammatical, mainly), while $33 \%$ (4/12) claimed to search for typing errors (punctuation and spelling). Also, 16.66\% (2/8) claimed that they ask for written feedback, either from others (classmates, relatives, and friends) or from the teacher, when corrective comments and suggestions are not part of the teaching plan elaborated by the instructor. Furthermore, $8.3 \%$ (1/8) of the subjects mention that they ask for assistance from friends and relatives to serve as either editors or some sort of audience to identify grammatical/lexical-related issues or ideas that might be unclear, while authors read their own text aloud (refer to Figure 3).

It is important to bear in mind that all HLLs claim that they usually review their texts during and after constructing them. In this regard, participants tended to monitor, edit, and amend their texts both during and after completing the writing process. As to the focus of the revisions, the actions involved in the writing process, as observed in the videos, were consistent with two of the as- 


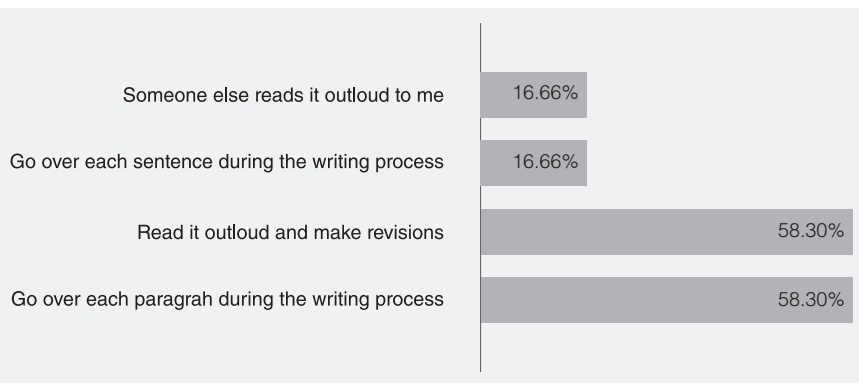

FIGURE 2. Strategies allegedly applied by the participants while crafting any text in Spanish

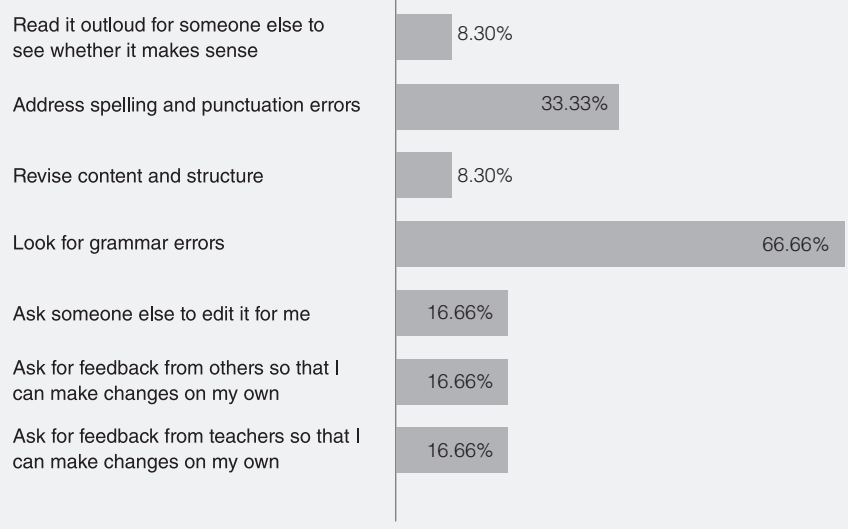

FIGURE 3. Most common post-writing revision strategies reportedly used by the participants when writing any text in Spanish

sertions shared by participants in the initial online survey. As such, the changes carried out by the participants of this study mainly addressed mechanic concerns (i.e., spelling) $(9 / 12=75 \%)$, grammar-related matters $(7 / 12=58.30 \%)$, and content issues $(6 / 6=50 \%)$. The latter was intended particularly to make texts more fluid and better organized, as seen in Figure 4. It is worth noting that spelling and grammar issues were widely addressed by using the correction tool in Microsoft Word. 
Content (fluency and organization)

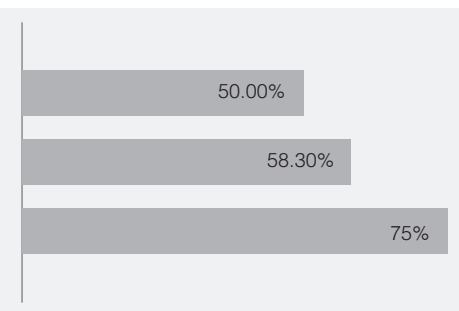

FIGURE 4. Focus of the revisions carried out when completing the assignment pertaining this study

\subsection{Research question 4: Efficacy of the planning and revision strategies used}

As previously noted, one of the aims of this research project was to determine the factors that accounted for the efficacy of texts. To this end, two one-way ANOVAs were carried out (Table 3). As for the efficacy of planning, the results of the first ANOVA suggested that the relationship between pre-writing preparation and the overall efficacy of texts was not statistically significant $(F=0.39$; $d f=1 ; p>0.847)$.

TABLE 3. Descriptive statistics: Relationship between planning and writing efficacy

\begin{tabular}{lcccccccc}
\hline & N & Mean & $\begin{array}{c}\text { Standard } \\
\text { Deviation }\end{array}$ & $\begin{array}{c}\text { Standard } \\
\text { ErRor }\end{array}$ & $\begin{array}{c}\text { Lower } \\
\text { Bound }\end{array}$ & $\begin{array}{c}\text { Upper } \\
\text { Bound }\end{array}$ & Min. & Max. \\
\hline Planning & 3 & 70.3333 & 8.0829 & 4.6666 & 50.2543 & 90.4124 & 61.00 & 75.00 \\
No planning & 9 & 67.8889 & 20.3558 & 6.7852 & 52.2420 & 83.5358 & 27.00 & 92.00 \\
Total & 12 & 65.5000 & 17.7328 & 5.1190 & 57.2331 & 79.7669 & 27.00 & 92.00 \\
\hline
\end{tabular}

Given that all participants carried out some sort of revision at some point during the writing process, subject performances were sorted into two groups (A and B) to gain a deeper understanding of which type of revision had a higher positive impact, if any. Group A included subjects that focused their revisions only on linguistic accuracy (i.e., grammar-related issues) and mechanics (i.e., spelling, written accent placement and punctuation). Group B included subjects who did not only carry out linguistic and mechanical revisions, but also made adjust- 
ments related to actual text content (i.e., organization, cohesion, coherence, and fluency of the ideas); refer to Table 4.

Table 4. Descriptive statistics: Relationship between revision and writing efficacy

\begin{tabular}{|c|c|c|c|c|c|c|c|c|}
\hline & $\mathrm{N}$ & MEAn & $\begin{array}{l}\text { Standard } \\
\text { DeVIATION }\end{array}$ & $\begin{array}{c}\text { Standard } \\
\text { ERroR }\end{array}$ & $\begin{array}{l}\text { LOWER } \\
\text { BoUND }\end{array}$ & $\begin{array}{l}\text { UPPER } \\
\text { BoUND }\end{array}$ & MIN. & Max. \\
\hline $\begin{array}{l}\text { Linguistic, } \\
\text { mechanics, and } \\
\text { content-related } \\
\text { revisions }\end{array}$ & 6 & 80.1667 & 9.3683 & 3.8246 & 70.3351 & 89.9982 & 70.00 & 92.00 \\
\hline $\begin{array}{l}\text { Linguistic and } \\
\text { mechanics } \\
\text { revisions }\end{array}$ & 6 & 56.8633 & 16.6543 & 6.7991 & 39.5557 & 74.3110 & 27.00 & 75.00 \\
\hline Total & 12 & 68.5000 & 17.7328 & 5.1190 & 57.3331 & 79.7669 & 27.00 & 92.00 \\
\hline
\end{tabular}

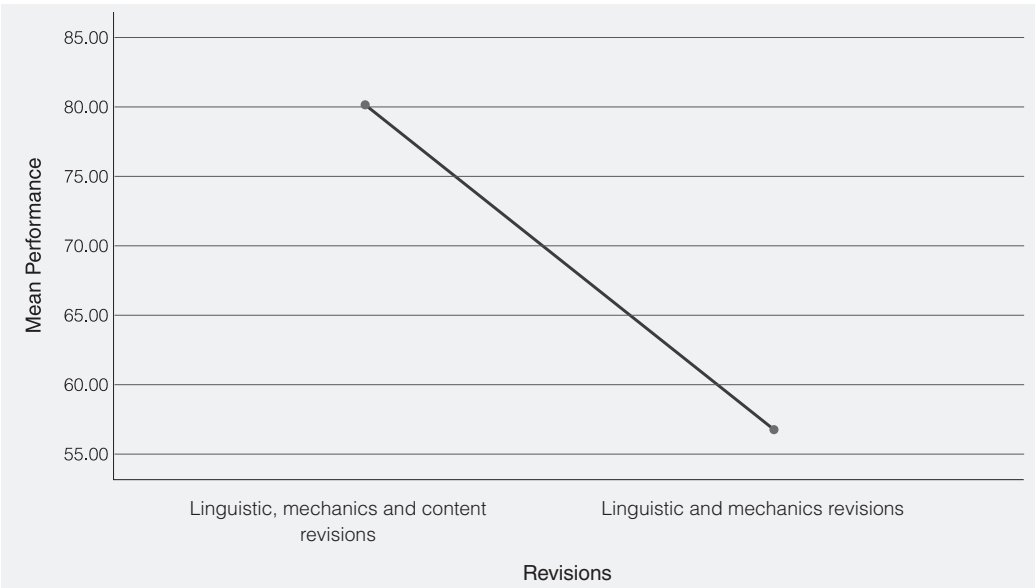

FIGURE 5. Relationship between content and non-content revisions

The correlation between revisions focused on linguistic and mechanical aspects only vs. revisions on linguistics, mechanical, and content issues was statistically significant $(F=8.947 ; d f=1 ; p \leq 0.014)$. This suggests that revisions focused on content-related matters contributed to higher overall efficacy in some texts. 
This significance was further confirmed by a Robust Test of Equality of Means $(d f 2=7.876 ; d f 1=1 ; p \leq 0.018$; refer to Figure 5).

\section{Discussion}

The results observed here are in line with Schwartz (2003) in terms of time allocation, given that participants in this study also dedicated most of the time allowed to the composing stage. Additionally, similar to Mikulski and Elola (2011), writers who conducted more meaningful revisions — which in this case involved focusing not only on grammatical and mechanical issues, but also on content-related aspects (i.e., organization, cohesion, coherence) - produced more effective and accurate texts.

The self-perception of participants about their own writing skills was a poor predictor of their actions when planning their texts. More specifically, of the four HLLs that reported conducting some sort of preparation (e.g., an outline) regularly before constructing any text in Spanish, half considered themselves to be effective writers (participants 005 and 043). The other half perceived themselves as being low-skilled authors (participants 018 and 033). A surprising finding, however, was the fact that none of those who claimed to routinely engage in planning activities before completing their texts, did so when crafting the argumentative essay of this study. The perceptions of the complexity level of the assignment itself seemed to have 'prevented' these four HLLs from conducting any pre-writing planning, as all of them considered that the task involved no difficulties. It is worth pointing out that two out of the three HLLs (participants 002, 012 and 037) who actually carried out an evident preparation before completing the argumentative text consider themselves as ineffective writers (participants 002 and 037). As mentioned above, these two HLLs had this self-perception either because they were aware of their limited linguistic knowledge of the heritage language (participants 002, 012), or simply because they have had limited opportunities to write in Spanish (participant 037). Surprisingly, participant 037, who had virtually no experience in writing in the HL and no formal experience with academic writing in Spanish, still used a writing strategy that included a planning stage (e.g., gathering information). All these observations ultimately 
suggest that most HLLs are fluid writers that do not approach the writing process according to a strategic plan.

As regards the challenges that participants faced, their self-perceptions were mostly consistent with their realities. Specifically, the overall quality of the final text showed that mechanic (i.e., spelling, accent placement, and punctuation) and grammar-related issues were real. However, across essays, there was a constant constraint that seemed to have been generally overseen: processing a limited lexicon. Only participant 047 was aware of this situation, as suggested by the following statement when describing his skills as a writer: "expanding my Spanish vocabulary could make my writing more effective". A narrow lexical baseline may actually make some electronic tools inefficient and detrimental. For instance, when crafting her text, participant 002 attempted to use the Spanish verb escoger (to choose); however, when doing so, she made a common mistake among Spanish HLLs, by misusing a " $\mathrm{j}$ " instead of a "g", thus typing escojer. At first glance, this mistake may be perceived as an easy-spelling fix. However, relaying on the correction options provided by Microsoft Word, participant 002 ended up picking the first choice available, escomer (to be eaten up, as in becoming eroded or rotten). This was not the only instance in which such occurrence took place. A similar behavior was observed in the performance of participants 005, 018 and 035. It can be assumed that HLLs likely have a shared understanding that the first couple of options displayed by the electronic tool may be the most accurate/adequate selections. What seems reasonable to state is the fact that the limited mechanic writing skills (both spelling and accent placement) of HLLs could also influence their understanding of the lexicon, and vice versa. This issue ultimately made the Microsoft Word spelling tool to become a disadvantage rather than a resource, which in several instances affected the precision and quality of the message conveyed through argumentative texts.

Within the area of research on writing skills in Second Language Acquisition (SLA), there is a shared perception amongst scholars: in order to develop literacy in a L2, it is crucial to avoid approaching writing as a product; instead, it requires implementing its practice as a process (Storch, 2013; Williams, 2012), that is, through different phases (e.g., planning, composing, and revision). Based on this understanding, learners should be stimulated to develop 
and execute both the planning and revision stages (Norris \& Manchón, 2012; Williams, 2012) while crafting any text. However, when comparing the efficacy of these two stages of the writing process, only revision practices reached statistical significance for the construction of effective essays. Subsequently, only comprehensive revisions led to supported argumentative essays, that is, modifications and changes focused not only on mechanics (i.e., spelling, accent placement, and punctuation) and grammar-related aspects, but also with content issues (i.e., organization, fluency, and cohesion).

\section{Pedagogical implications}

Some pedagogical recommendations to address writing in the HL classroom that derive from the results outlined here are the following. First, the exposure to Spanish that HLLs experience at home develops in a context in which is not only natural, but also casual (Beaudrie, Ducar \& Potowski, 2014); consequently and regarding lexicon, HLLs lack a formal register and an broad lexical baseline. This potentially obscures the meaning of texts produced by HLLs, as evidenced in this study. In order to empower them as writers, HLLs vocabulary repertoire should be expanded through activities such as the one included in Appendix A: how do you spell it and what does it mean. This activity aims to promote the exploration of lexicon and the reflection of its meaning based on prefixes, suffixes, base words and the grammatical nature thereof, that is, whether base words function as adjectives, nouns, verbs, adverbs, and so on, according to the context. Specifically, this activity requires a three-stage process: 1) crafting/adding mistaken sentences, 2) engaging in a reflection process, and 3) correcting errors.

Regarding stage 1), it should be noticed that the activity starts by presenting a sentence including the same spelling error made by participant 002 when writing escoger (to choose), but misspelling it with " $\mathrm{j}$ " instead of " $\mathrm{g}$ ". This mistake ultimately diverted the meaning of the whole sentence. As for stage 2 ), instructors must encourage learners to recognize the base words and any prefixes and suffixes linked to all the options offered in the gray box (e.g., escomer, escoger, and escocer) - simulating the correction tool of Microsoft Word. In the case of escomer, for instance, the base word would be comer (to eat). Afterwards, learners should be motivated to understand the meaning of the 
lexical unit involved, either by writing down a short definition or by finding a synonym. For example, consumir (i.e., to consume) could be use as an equivalent of comer (i.e., to eat). Subsequently, instructors should require learners to find a replacement for the previously established definitions/synonyms, such as desgastar(se) (i.e., to wear out) for consumir (i.e., to consume). Based on this knowledge, learners should have to complete the last stage: correcting errors in original sentences. To do so, they should be asked to determine which of the three options displayed in the gray box (e.g., escomer, escoger, and escocer) conveys the right meaning according to the context - escoger, in this example. In addition, learners should support their answers (as seen in Paso 2), so that they undergo a reflection process that reinforces the comprehension of previously unknown words. It is also recommended to ask learners to write two original sentences with words different from those used in the correction stage (refer to Paso 3), aiming to establish contextual connections with the new lexicon. When the activity is completed, learners will have automatically engaged in a conscious effort to expand their vocabulary by either inferring or looking up the meanings of varied words. They will also have established definitions, finding synonyms, and using the new lexicon in specific contexts.

To recreate an activity like the one included in Appendix A, the errors included by instructors should resemble lexical and spelling mistakes representing a constant challenge for HLLs. Some options include, but are not limited to, false cognates (e.g., realizar vs. darse cuenta; atender vs. asistir; aplicar vs. solicitar), or words that require the discrimination of spelling couplets/triplets like "v"/"b"; "c"/"z"/"s" or "j"/"g", especially those that may convey homophones (e.g., tuvo - he/she had vs. tubo - tube).

As for the stimulation of revisions focused on content, in addition to lexical precision, learners should be motivated to conduct self-assessments of their own written work before delivering them. A sample of this is provided in Appendix $\mathrm{B}$, where we include a task that involve four elements/sections that learners should reflect on:

a) communicative purpose (i.e., whether the text reflects a purposeful message),

b) text structure (e.g., whether it includes an introduction, transitions, a conclusion, and so on), 
c) cohesive resources used (e.g., identifying the connectors used and their functions),

d) vocabulary effectiveness (e.g., avoiding false cognates, or avoiding repeating words by using synonyms).

As of the communicative purpose (clause "a"), learners should be required to state such aim, or express what they attempted to achieve with their written assignments, if they face complications identifying the main communicative purpose(s). Carrying out these types of reflections would not only facilitate the revision process, but would also promote a higher level of autonomy when doing so.

\section{Limitations}

Despite the novelty of the study presented here, there are some limitations that should be considered when conducting further research on the self-perceptions and performances of HLLs as writers in Spanish. First, the recommended number of participants should be larger than twelve, in order to confirm the validity of the results observed here across a wider spectrum within the linguistics arena. It should be kept in mind that the present study was conducted in the Midwest of the United States of America. Thus, future studies on similar topics should involve HLLs from other areas or countries. As previously mentioned, persuasion was the chosen text genre for this study, given that most subjects were familiar with the writing features and requirements involved in constructing this type of essay. Additionally, persuasive texts require an overall high cognitive demand that presumably entails a deeper engagement from writers. However, in order to keep advancing the knowledge on (the effectiveness of) the writing strategies employed by HLLs when using Spanish, as well as developing a more profound consciousness of the self-perspective of HLLs as authors, other academic writing genres should be surveyed (i.e., expository or research papers). Also, a process that may shed more light on the investigation of HLL writing in Spanish should standardize the writing process for all subjects, that is, all participants must be asked to involve similar writing stages when completing a text. This was not the case in the present study, where participants freely chose whether 
or not to plan/revise, which ultimately led to different degrees of planning and revision.

\section{Conclusion}

HLLs are well aware of their own limitations as writers and the most challenging issues they commonly face when crafting texts in Spanish, such as dealing with mechanical and grammar-related issues. However, this study suggests that they tend to be fluid writers who approach text crafting randomly instead of following a strategic plan. Thus, the self-perceptions of HLLs on how they approach the writing process (i.e., planning, composing, and revision) may not always match their realities. In fact, several HLLs in this study seemed to be aware of the importance of elaborating some sort of previous plan or blueprint of their written work. However, only three participants actually carried out some sort of preparation. None of these three people belonged to the group of subjects that had previously claimed to conduct pre-writing planning. Also, despite being well acquainted with most of their limitations, these writers seemed to be unaware of how narrow their lexicon repertoire is, leading to the improper use of revision tools, such as the spelling and grammar correction feature in Microsoft Word, that ultimately contribute to defective texts.

As regards revisions, more HLLs actively make changes to their texts at some point of the writing process, as compared to those who engaged in some sort of planning tasks. However, only half of the participants focused on in-depth matters (i.e., content). As this specific type of corrections was associated to the construction of more effective argumentative texts, this study urges instructors to exhaustively focus on the development of efficient strategies to address issues related to cohesion, coherence and fluidity, in addition to grammatical and lexical-related difficulties. For this to happen, however, Spanish instructors themselves should have a sound knowledge on the implications of literacy development. This awareness will contribute to develop the degree of sensibility needed about the complexity involved in mastering writing (as a linguistic skill). This knowledge and sensibility will, consequently, set the grounds to further the literacy of learners in the Spanish HL classroom (Spicer-Escalante, 2011). 
Based on the above, it is imperative that in the heritage classroom setting, Spanish instructors implement various ongoing activities and tasks to facilitate the broadening of lexical knowledge, as well as the autonomous and effective revision of texts as a whole, thus focusing on mechanics, grammar-related matters, and content quality, in order to ultimately empower Spanish HLLs as writers.

\section{References}

Blake, Robert, \& ZyziK, Eve (2003). Who's helping whom?: Learner/heritage-speakers' networked discussions in Spanish. Applied Linguistics, 24(4), 519-544.

Beaudrie, Sara; Ducar, Cynthia, \& Potowski, Kim (2014). Heritage language teaching: Research and practice. New York: McGraw-Hill Education Create.

Callahan, Laura (2010). U.S. latino's use of written Spanish: Realities and aspirations. Heritage Language Journal, 7(1), 1-27.

Chevalier, Joan (2004). Heritage language literacy: Theory and practice. Heritage Language Journal, 2(1), 26-44.

Colombi, María Cecilia, \& Harrington, Joseph (2012). Advanced biliteracy development in Spanish as a heritage language. In Sara Baudrie \& Marta Fairclough (Eds.), Spanish as a Heritage Language in the United States: The state of the field (pp. 241-258). Washington: Georgetown University Press.

Connor, Ulla, \& LAUer, JANice (1985). Cross-cultural variation in persuasive student writing. En A Purves \& Cecilia Colombi (Ed.), Writing across languages and cultures: Issues in contrastive rhetoric (pp. 138-159). Newbury Park: Sage.

Elola, Idoia, \& Mikulski, Ariana (2013). Revisions in real time: Spanish heritage language learners' writing processes in English and Spanish. Foreign Language Annals, 46(4), 646-660. García, Ofelia (2002). Writing backwards across languages: The inexpert English/Spanish biliteracy of uncertified bilingual teachers. En Mary Schleppegrell \& Cecilia Colombi (Eds.), Developing advanced literacy in first and second languages (pp. 245-259). Mahwah: Lawrence Erlbaum.

LIPSKI, JoHN (2008). Varieties of Spanish in the United States. Washington: Georgetown University Press.

Mikulski, ARIANA, \& ElolA, IdOIA (2011). Spanish heritage language learners' allocation of time to writing processes in English and Spanish. Hispania, 94(4), 715-733. 
Montrul, Silvina, \& Bowles, Melissa (2009). Back to basics: Differential object marking under incomplete acquisition in Spanish heritage speakers. Bilingualism: Language and Cognition, 12(3), 363-383.

NoRris, John M, \& MANCHÓN, Rosa (2012). Investigating L2 writing development from multiple perspectives: Issues in theory and research. In Rosa María Manchón (Ed.), L2 writing development: Multiple perspectives (pp. 221-244). Berlin: De Gruyter Mouton.

Pascual y Cabo, Diego, \& Rothman, Jason (2012). The (Il)logical problem of heritage speaker bilingualism and incomplete acquisition. Applied Linguistics, 33(4), 450-455.

Schwartz, Ana María (2003). ¡No me suena! Heritage Spanish speakers’ writing strategies. In Ana Roca \& María Cecilia Colombi (Eds.), Mi lengua: Spanish as a heritage language in the United States, research and practice (pp. 235-256). Washington: Georgetown University Press.

SPICER-Escalante, María Luisa (2005). Writing in two languages / living in two worlds: A rhetorical analysis of Mexican-American written discourse. In Marcia Farr (Ed.), Latino language and literacy in ethnolinguistic Chicago (pp. 217-244). Mahway: Lawrence Erlbaum Associates.

Spicer-Escalante, María Luisa (2011). Revising our curriculum/empowering students: Teachers' preparation and perceptions about bilingual writing. Theory and Practice in Language Studies, 1(11), 1453-1458.

Spicer-Escalante, María Luisa (2015). Exploración de las narrativas bilingües orales y escritas en español e inglés. Zona Próxima, 23, 18-30.

Storch, NeOmy (2013). Collaborative writing in L2 classrooms: New perspectives on language and education. Bristol: Miltilingual Matters.

Strobl, Carola (2014). Affordances of web 2.0 technologies for collaborative advanced writing in a foreign language. CALICO Journal, 31(1), 1-18.

VALdÉs, GuAdALuPE (1997). The teaching of Spanish to bilingual Spanish-speaking students: Outstanding issues and unanswered questions. In María Cecilia Colombi \& Francisco Xavier Alarcón (Eds.), La enseñanza del español a hispanohablantes: praxis y teoría (pp. 8-44). Boston: Houghton Mifflin.

Valdés, Guadalupe (2001). Heritage language students: Profiles and possibilities. In Joy Kreeft Peyton, Donald Ranard \& Scott McGinnis (Eds.), Heritage language in America: Preserving a natural source (pp. 37-77). McHenry: The Center for Applied Linguistics and Delta Systems.

VALDÉs, GuAdALUPE (2005). Bilingualism, heritage language learners, and sLA research: Opportunities lost or seized? The Modern Language Journal, 89(3), 410-426.

Venezuela, Elena; Faure, Ana Margarita; Ramírez-Trujillo, Alma P.; Barski, Ewelina; Pangtay, Yolanda, \& DíEz, Adriana (2012). Gender and heritage Spanish bilingual gram- 
mars: A study of code-mixed determiners phrases and copula constructions. Hispania, 95(3), 481-494.

WiLliams, JessiCA (2005). Teaching writing in second and foreign language classrooms. Boston: McGraw-Hill.

Williams, Jessica (2012). The potential role(s) of writing in second language development. Journal of Second Language Writing, 21(4), 321-331.

\section{Appendix}

\section{A. How do you spell it and what does it mean}

Paso 1. Mira las siguientes opciones para que determines el significado de cada una de las palabras sugeridas por la herramienta de correcciones de Microsoft Word y así puedas elegir la opción adecuada de acuerdo con el contexto. Se recomienda que uses el diccionario en línea de la Real Academia (www.rae.es).

1. Voy a escoher la meinr nnción disnnnible.

$$
\begin{aligned}
& \text { escomer } \\
& \text { escoger } \\
& \text { escocer }
\end{aligned}
$$

\begin{tabular}{|l|l|l|}
\hline Escomer & Significado de la base verbal & \\
\hline Base verbal & \\
\hline Significado de la palabra & & \\
\hline Sinónimo & & \\
\hline
\end{tabular}

\begin{tabular}{|l|l|l|}
\hline Escoger \\
\hline Base verbal & Significado de la base verbal & \\
\hline Significado de la palabra & & \\
\hline Sinónimo & & \\
\hline
\end{tabular}




\begin{tabular}{|l|l|l|}
\hline Escocer & \multicolumn{2}{|l|}{} \\
\hline Base verbal & & Significado de la base verbal \\
\hline Significado de la palabra & & \\
\hline Sinónimo & & \\
\hline
\end{tabular}

Paso 2. Contesta las siguientes preguntas:

¿Qué opción debes seleccionar?

¿Por qué?

Paso 3. Por favor, usa las dos palabras que no seleccionaste para escribir una oración con cada una de ellas:

Oración 1:

Oración 2:

B. Writing self-assessment

Self-assessment questionnaire

1. What is the communicative purpose of the assignment?

(Version A)

2a. Did you accomplish this goal? Yes / No

If you answered "yes", how did you do it? For example: I described information about the academic advantages and disadvantages of each institution.

If you answered "no"...

I. Can you explain why? 
II. What could you do differently to achieve the original goal of the assignment?

(Version B)

2b. Did you accomplish this goal? Yes/No

To help you answer this question, check all the options that apply to the content of your text.

I included a thesis statement that states the aim of my text.

I provided at least two arguments to persuade my audience.

I backed up my arguments with at least one/two supporting ideas.

My supporting ideas were based on facts that I researched, rather than being limited to my personal experience only.

My arguments addressed both academic and non-academic matters.

3. Did you present your ideas effectively? To help you answer this question, check all the options that apply to the content of your text.

I started my composition with a formal greeting. .***

I wrote an introduction where I provided a thesis statement and an overall organization/sequence of the text.

I included a conclusion where I wrapped up my ideas.

I included a conclusion where I reinforced my thesis statement.

The transitions between my ideas and paragraphs are effective; for example, I used connectors such as: "on the other hand"; , which

served to: "introduce a contrasting idea"; 
4. To make your text cohesive, please specify which transition words or expressions you used for each of the following categories:

Consequence:

Exemplifying:

Emphasis:

Similarity:

Restatement:

Contrast and comparison:

Sequence:

Summarizing:

5. Did you use a varied vocabulary? To answer this question, please consider the following:

When reading your text, do you find words that appear multiple times consecutively? Yes / No. If so, please list those words here and provide a synonym for each of them.

\begin{tabular}{|l|l|}
\hline Repetitive word(s) & Synonym \\
\hline 1. & \\
\hline 2. & \\
\hline
\end{tabular}

Did you use cognates? Yes/No. If so, did you use them accurately? To answer this question, please list them and provide a definition for each of the cognates in the right column. Is that what you meant to say?

\begin{tabular}{|l|l|l|}
\hline Cognates & Definition & $\begin{array}{l}\text { It reflects what I meant to } \\
\text { say... (Y/N) }\end{array}$ \\
\hline 1. & & \\
\hline 2. & & \\
\hline
\end{tabular}


Are you unsure about the spelling of specific words? Yes/No. If so, please list them here; write down all the possible spelling variations of each word; look up each of your possibilities on a dictionary: www.rae.es

\begin{tabular}{|l|l|l|l|}
\hline Word to check & Spelling variations & Meaning & $\begin{array}{c}\text { Which is the correct } \\
\text { spelling? }\end{array}$ \\
\hline 1. & & & \\
\hline 2. & & & \\
\hline
\end{tabular}

